\title{
THE MICROTRABECULAR LATTICE OF THE ADRENAL MEDULLA REVEALED BY POLYETHYLENE GLYCOL EMBEDDING AND STEREO ELECTRON MICROSCOPY ${ }^{1}$
}

\author{
HISATAKE KONDO, JOHN J. WOLOSEWICK, AND GEORGE D. PAPPAS ${ }^{2}$ \\ Department of Anatomy, University of Illinois at the Medical Center, Chicago, Illinois 60612
}

Received April 29, 1981; Revised September 21, 1981; Accepted September 21, 1981

\begin{abstract}
Stereo transmission electron microscopy of polyethylene glycol (PEG)-embedded rat adrenal medulla reveals the ground cytoplasm of chromaffin cells and preganglionic nerve endings to be a three-dimensional lattice of microtrabeculae that is contiguous with the surface of chromaffin granules and synaptic vesicles and also with the plasma and presynaptic membranes. The microtrabeculae, because of their association with the granules and vesicles, are implicated with the translocation of these structures as well as in the secretion and release of catecholamines and other neurotransmitters.
\end{abstract}

A current belief is that the release of secretory products and transmitters from endocrine cells and nerve endings occurs after a directed deployment of secretory granules and synaptic vesicles toward the inner surface of the plasma membrane (cf., Pappas and Waxman, 1972; Heuser and Reese, 1977). Moreover, it has been suggested that there is a structural organization in endocrine cells and nerve endings which serves as an internal pathway for the movement of the secretory granules and synaptic vesicles. Although the presence of filamentous networks has been reported in neurons (Ellisman and Porter, 1980; LeBeux and Willemot, 1975a, b), these are poorly defined in conventional electron microscopic images of epoxyembedded preparations. This is due in large part to the electron-scattering properties of the epoxy resin in addition to the inability to add sufficient contrast to the embedded structures.

The cytoplasmic ground substance of whole, unembedded, critical-point dried cultured cells has been interpreted to have an organized structure (Wolosewick and Porter, 1976, 1979). This structured cytoplasmic ground substance consists of slender strands, termed microtrabeculae, which, together with cytoskeletal and membranous organelles, form an irregular three-dimensional lattice, i.e., the microtrabecular lattice (MTL; Wolosewick and Porter, 1976, 1979). The microtrabeculae vary from

\footnotetext{
' This work was supported by National Institutes of Health Grants NS 16610 and GM 28397.

${ }^{2}$ To whom correspondence should be addressed at Department of Anatomy, University of Illinois at the Medical Center, 808 South Wood Street, Chicago, IL 60612.
}

3 to $12 \mathrm{~nm}$ in diameter and are over $50 \mathrm{~nm}$ in length. They are contiguous with the membranous and nonmembranous organelles and are confluent with the cortices of the cytoplast. The microtrabeculae represent the nonrandom organization of the cytoplasmic ground substance of living cells (Wolosewick, 1980). A similar lattice structure was demonstrated in resin-less, thin-sectioned preparations using the polyethylene glycol (PEG)-embedding method which enhances remarkably the appearance of the cytoskeletal structures (microtrabeculae, microtubules, microfilaments, and intermediate filaments; Wolosewick, 1980).

Before addressing the possibility that the microtrabecular lattice might be involved in the movement of the granules and vesicles, we sought a description of the MTL in chromaffin cells and preganglionic nerve endings. This study utilized the PEG-embedding method and stereo electron microscopy. A specific, contiguous association of the microtrabeculae with chromaffin granules and synaptic vesicles, as well as the plasma membrane, is described.

\section{Materials and Methods}

Adult albino rats weighing $150 \mathrm{gm}$ were anesthetized by intraperitoneal injection of pentobarbital and fixed by whole body vascular perfusion with $2.5 \%$ glutaraldehyde buffered in $0.1 \mathrm{~m}$ sodium cacodylate $(\mathrm{pH}$ 7.4). The adrenals were removed $10 \mathrm{~min}$ after perfusion, minced in fresh fixative, and immersed in the fixative for an additional $2 \mathrm{hr}$. The tissues were subsequently bathed for 2 $\mathrm{hr}$ in $2.5 \%$ glutaraldehyde containing $0.5 \%$ tannic acid in the sodium cacodylate buffer. The blocks were washed 
in the buffer ( $1 \mathrm{hr}$ ), postfixed in $1 \%$ buffered osmium tetroxide for $2 \mathrm{hr}$, and stained (1 hr) en bloc with $1 \%$ aqueous uranyl acetate. The blocks were dehydrated in ethyl alcohol. Three separate protocols were subsequently followed.

$P E G$ embedding. The blocks in absolute alcohol were transferred to a $50 \%$ solution of PEG-6000 (Sigma Chemical Co., St. Louis, MO) in $100 \%$ absolute ethanol (v/v) and infiltrated (vials uncovered) for $12 \mathrm{hr}$ at $60^{\circ} \mathrm{C}$. The blocks were transferred to pure molten PEG for $2 \mathrm{hr}$, embedded in PEG contained in well dried gelatin capsules, and rapidly solidified by immersion in swirling liquid nitrogen. Sections were made with glass knives using a Sorvall MT-1 ultramicrotome and mounted onto Formvar-coated grids which had been treated with polyL-lysine $(0.1 \%$ in distilled water). The mounting of the sections and removal of the PEG from the sections was carried out in a solution of $95 \%$ ethanol containing $5 \%$ PEG. The grids were placed in a muliple grid holder and transferred into 95\% ethanol. After exchanging the 95\% ethanol with absolute ethanol several times, the grids were dried either by the critical point process from $\mathrm{CO}_{2}$ (Wolosewick, 1980) or by desiccator dried from Freon (Becker et al., 1981). The dried grids were stabilized by carbon evaporation and observed with a JEOL-100 CX electron microscope operated at $100 \mathrm{kV}$.

Epon embedding. Tissues fixed and dehydrated as described above were treated with three changes of propylene oxide (10 min each), infiltrated, and embedded in Epon 812. Thin sections were cut with diamond knives on a Sorvall MT-2 ultramicrotome, mounted on uncoated 300 mesh copper grids, stained with aqueous uranyl acetate and lead citrate, and viewed in the JEOL-100 CX electron microscope.

PEG-Epon control. Specimens embedded in PEG were soaked in warm $95 \%$ ethyl alcohol for $2 \mathrm{hr}$. This is sufficient time for the removal of the PEG. The specimens were treated in propylene oxide, infiltrated, embedded in Epon, and sectioned as described above.

\section{Observations}

Electron microscopic images of PEG-processed adrenal medulla reveal a cytoplasmic organization very similar to that seen in thin sections of conventional epoxy-embedded preparations. Figures 1 and 2 illustrate cells at low magnification from the rat adrenal medulla processed through PEG and Epon, respectively.

The nuclei of chromaffin cells are round to ellipsoidal, often with prominent nucleoli and abundant heterochromatin at the nuclear envelope. Chromaffin granules, elongated mitochondria with dense matrices, unmyelinated axons, and preganglionic nerve endings can be identified at low magnification. Although there appear to be slight qualitative differences between these images, it is re- markable that the contrasty image in Figure 1 is a resinless, unstained section. The contrast of resin-less sections is far greater than that of epoxy sections of the same thickness.

The characteristic epinephrine and norepinephrine cells can be identified also in PEG-processed adrenal medulla. Use of the established morphological criteria of glutaraldehyde-fixed adrenal medulla (Elfvin, 1965; Coupland, 1965) reveals that epinephrine cells contain membrane-bound granules with matrices that are relatively homogeneous, exhibiting slight to moderate electron density. In contrast, norepinephrine cells possess membrane-bound chromaffin granules with eccentric, electron-dense cores (see Fig. 1). The cytoplasmic organization of the PEG-processed adrenal medulla appears to be well maintained.

At higher magnification, the unique features of the resin-less sections become readily apparent. For example, Figures 3 and 4 show portions of the cytoplasm of epinephrine cells. The epoxy-embedded sample (Fig. 3) shows the typical appearance of chromaffin granules, few cisternae of the rough endoplasmic reticulum, and a very flocculent cytoplasmic ground substance occupying the area between these organelles. Resin-less sections viewed in stereo also exhibit membrane-bound epinephrine-type granules (Fig. 4). However, in contrast to epoxy-embedded cells, the granules in resin-less sections are seen to be interconnected one to another by the structured components of the cytoplasmic ground substance, i.e., the microtrabeculae.

These structured components assume the appearance of fine strands measuring 3 to $12 \mathrm{~nm}$ in diameter and 35 to $180 \mathrm{~nm}$ in length and are equivalent to the microtrabeculae observed in whole-cultured cells and other resinless sections of cells viewed by high voltage electron microscopy (Wolosewick and Porter, 1976; Wolosewick, 1980). As in other resin-less preparations, the microtrabeculae form a three-dimensional lattice interconnecting cytoskeletal and membranous organelles. In Figure 4, the chromaffin granules are contained in the lattice and the lattice-trabeculae are viewed as contiguous with the limiting membrane of the chromaffin granules and with other microtrabeculae.

In favorable sections, the membranes of the chromaffin granules in both epoxy-embedded and resin-less sections exhibit the typical trilaminar unit membrane structure measuring 8 to $9 \mathrm{~nm}$ in thickness (Figs. 3 and 4). Frequently the membranes are not always distinct in resinless sections, and this is due to the fact that the sections are usually 150 to $200 \mathrm{~nm}$ thick. If such thick preparations are viewed at $100 \mathrm{kV}$ (high voltage electron microscope), the membranous components would often be more distinct.

The slight difference in the size of the chromaffin

Figure 1. Electron micrograph of a section from the rat adrenal medulla processed through PEG. This resin-less section shows the typical appearance of chromaffin cells. Both epinephrine and norepinephrine chromaffin cells are recognized. The difference in the shape of the granules is apparent (epinephrine granules, single arrowheads; norepinephrine granules, double arrowheads). A nerve fiber $(A x)$ is seen between the two chromaffin cells. The nucleus $(N)$ and mitochondria $(M)$ are prominent in this section. The integrity of the section and the cytoplasmic organization are well preserved in this resin-less section. Magnification, $\times 15,000$.

Figure 2. Electron micrograph of a typical thin section of rat adrenal medulla embedded in epoxy resin. The image shows a portion of an epinephrine cell containing the characteristic granules (arrowheads), mitochondria $(M)$, and nucleus $(N)$. A profile of a nerve ending with synaptic vesicles $(S V)$ is seen enclosed within the cytoplasm of the chromaffin cell. Nearby, a nerve fiber $(A x)$ is seen in the surrounding milieu. Magnification, $\times 15,000$. 

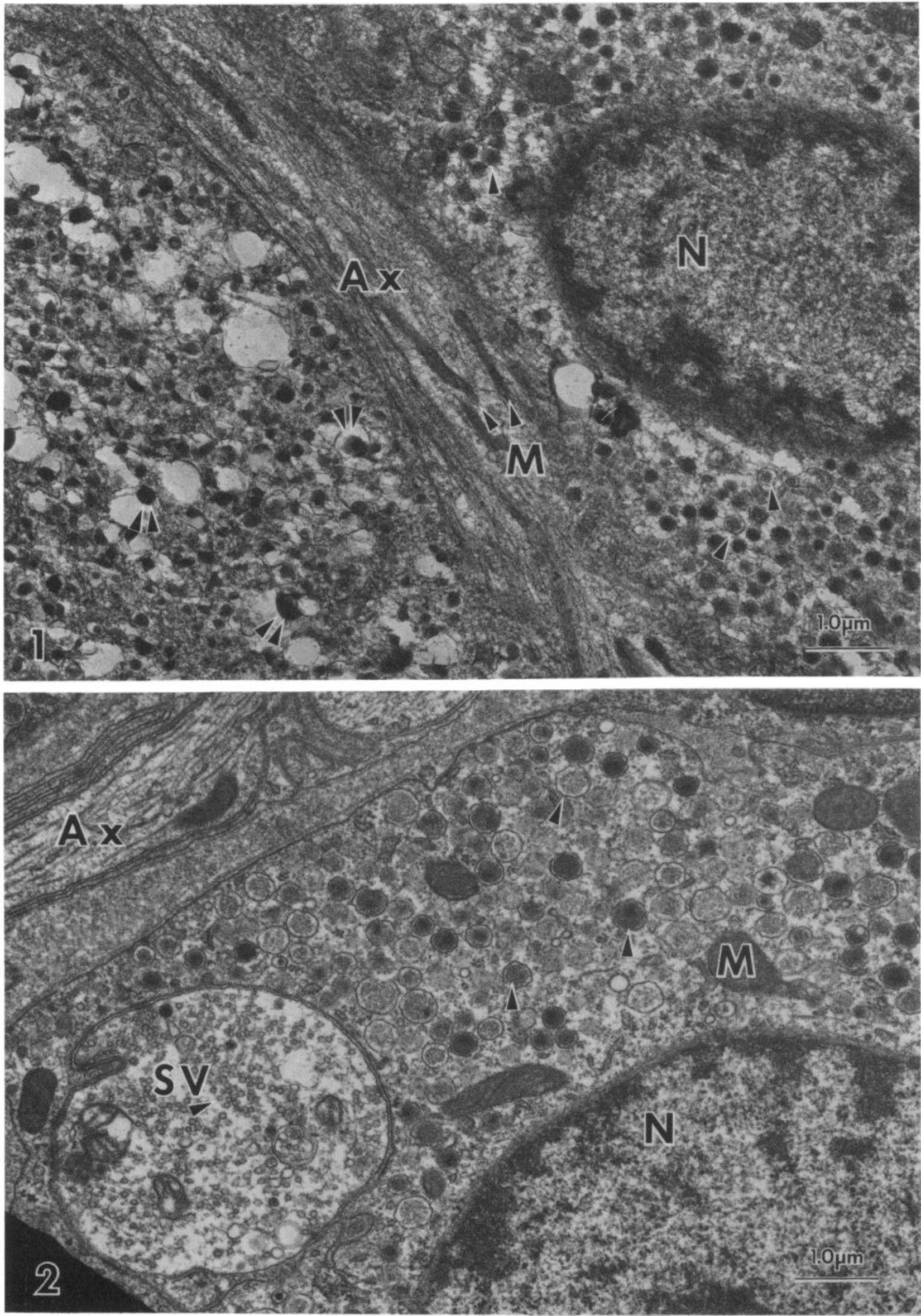

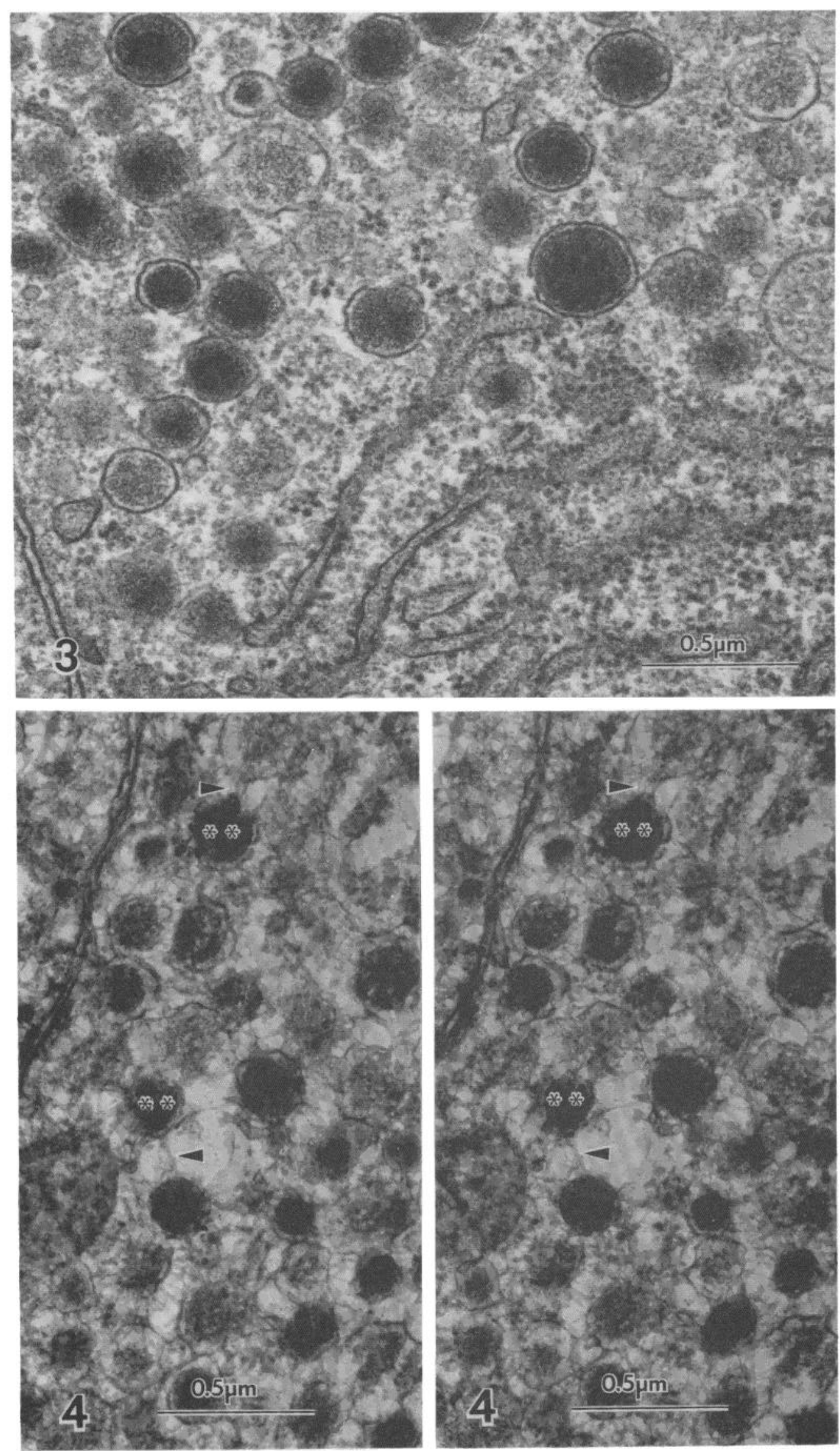
granules in resin-less and in epoxy sections may be related to specimen preparation. In resin-less sections, the epinephrine granules measure $250 \pm 39 \mathrm{~nm}$, and the norepinephrine granules measure $340 \pm 130 \mathrm{~nm}$. In epoxy sections, the epinephrine granules measure $283 \pm 46$, and the norepinephrine granules measure $370 \pm 120 \mathrm{~nm}$. These slight differences may be the result of some shrinkage distortion in the drying process. However, the spatial relationships of the granules and the cytoplasmic ground substance appear not to have been altered greatly.

The somewhat indistinct appearance of the membranes as well as the unique image of the cytoplasmic ground substance at high magnification compared with epoxy-embedded samples compelled us to check the ultrastructural quality of PEG-processed tissues by conventional techniques. Thus, blocks of PEG-embedded adrenal medulla tissue were de-embedded and subsequently processed for embedding in epoxy resin. Images of such preparations show little, if any, alteration in the cytoplasmic ultrastructure as is illustrated in Figure 5. The ultrastructural morphology of the epinephrine and norepinephrine cells, cytoplasmic membranes, mitochondria, and synaptic vesicles of preganglionic nerve endings as well preserved. Apparently, PEG embedding does not greatly alter cell ultrastructure.

Another feature common to the adrenal medulla is the

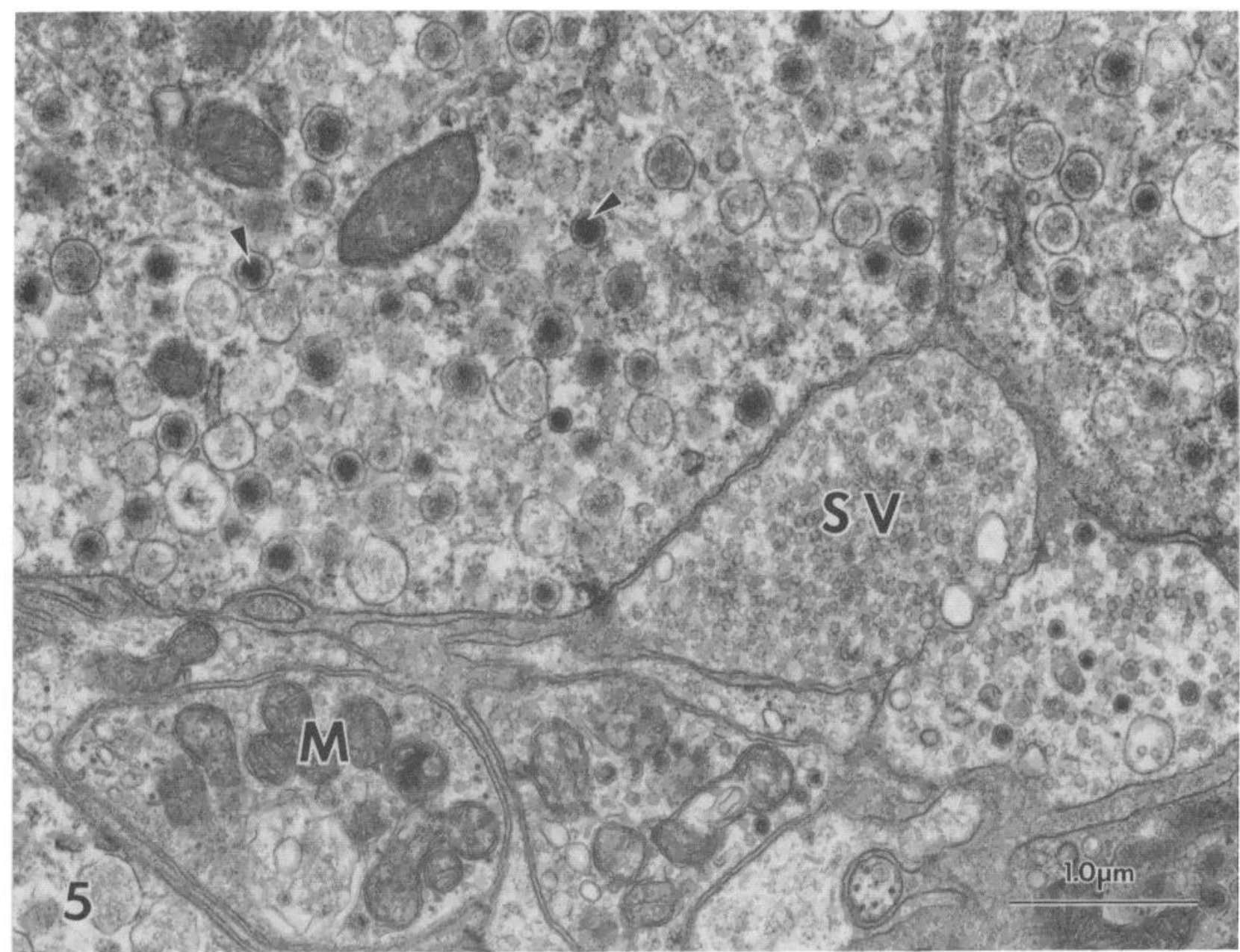

Figure 5. Electron micrograph of an adrenal medulla from a specimen which was processed first through PEG embedding and then subsequently de-embedded and processed for Epon embedding. This is a conventional thin section as seen in the electron microscope. The quality of preservation of cytoplasmic membranes, mitochondria, microtubules, and synaptic vesicles is excellent. Thus, PEG embedding does not greatly alter cell ultrastructure. $M$, mitochondria; $S V$, synaptic vesicles; arrowheads, chromaffin granules. Magnification, $\times 25,000$.

Figure 3. A high magnification image of a section of a chromaffin cell from epoxy-embedded adrenal medulla. This thin section shows epinephrine granules and a few cisternae of the endoplasmic reticulum. The electron translucency of the resin embedment produces a granular appearance to the area of the cell between the organelles, i.e., cytoplasmic ground substance. Magnification, $\times 50,000$.

Figure 4. Stereo electron micrograph of a portion of the cytoplasm from a chromaffin cell processed through PEG. The distinct difference between the epoxy-embedded sample (Fig. 3) and this resin-less section is apparent. In stereo, the granules (double asterisks) are seen to have matrices of varying density. The membranes of the granules are contiguous with the microtrabeculae (arrowheads). Note how the granules are interconnected one to another by the microtrabeculae, forming a three-dimensional continuum. Magnification, $\times 50,000$. 

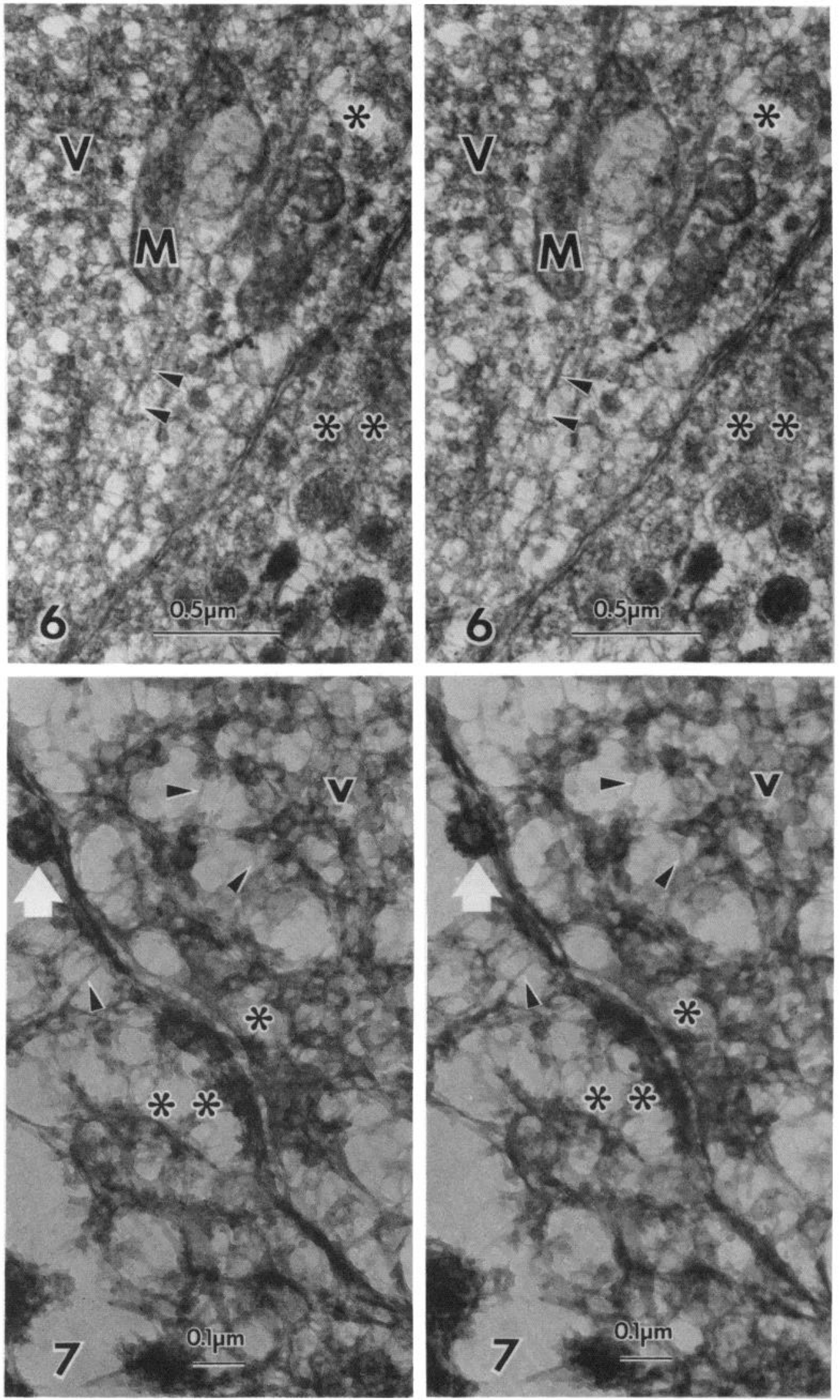

Figure 6. A stereo image of a preganglionic nerve ending of the cholinergic type as seen in PEG-processed adrenal medulla. The presynaptic region (marked by an asterisk) shows numerous small synaptic vesicles $(V)$ interconnected by the microtrabeculae. The microtrabeculae also are contiguous with the plasma membrane, microtubules (arrowheads), and mitochondria $(M)$. The postsynaptic region in the chromaffin cell is marked by a double asterisk. Considerable cleft material is present between these cells. The cytoplasm of the chromaffin cell is seen to be composed of numerous granules and the conspicuous microtrabecular lattice. Magnification, $\times 40,000$. 
presence of preganglionic nerve endings. Such endings are shown in epoxy-resin sections in Figures 2 and 5. These endings have been studied also in PEG-embedded adrenal medulla. Examples of these synapses onto chromaffin cells are shown in Figures 6 and 7.

In these stereo images, the three-dimensionality of the lattice structure is readily apparent. The presynaptic region is an anastomosing network of short filaments, i.e., the microtrabeculae, and numerous synaptic vesicles measuring $49 \pm 4 \mathrm{~nm}$ in diameter. In comparable epoxyembedded cells, the synaptic vesicles measure $53 \pm 3 \mathrm{~nm}$ in diameter. The membranes of the vesicles are contiguous with the microtrabeculae forming the characteristic lattice. Unlike other synapses (e.g., in the central nervous system; see Pappas and Waxman, 1972), microtubules and microfilaments are not commonly observed here in Epon sections. The lattice trabeculae are contiguous not only with the vesicles but also with the plasma membrane (i.e., the presynaptic membrane). The postsynaptic region, as in other synapses, is, marked by the postsynaptic density, an accumulation of flocculent, dense material of varied chemical composition (Cohen et al., 1977). Perforations of the postsynaptic density commonly observed in synapses in the central nervous system were not encountered in these cells (cf., Cohen and Siekevitz, 1978). The postsynaptic density and the plasma membrane of the chromaffin cells are contiguous with the microtrabecular lattice. Contained within the lattice, as already described, are the chromaffin granules and distinct coated pits (see Fig. 7).

\section{Discussion}

Resin-less sections of polyethylene glycol-processed adrenal medulla, viewed by stereo electron microscopy reveals the cytoplasmic ground substance of chromaffin cells and preganglionic nerve endings to be a three-dimensional lattice, the microtrabecular lattice. The membrane of the chromaffin granules and synaptic vesicles appear contiguous with the microtrabeculae of the lattice. In stereo, these images of the cytoplasm give one the impression that the granules and vesicles are "held in place" by the lattice. In contrast, in epoxy-embedded specimens, the microtrabeculae are not as clearly evident primarily due to the electron scattering (Wolosewick and Porter, 1979; Wolosewick, 1980).

The lattice observed here is equivalent to the microtrabecular lattice visualized in whole cells and resin-less sections of cells viewed by high voltage electron microscopy. It has been suggested that this lattice reflects the nonrandomness of the cytoplasmic ground substance and represents the fixed and dried ultrastructural correlate to what was present in the living cell (Wolosewick and Porter, 1976, 1979; Wolosewick et al., 1980).

The chemical composition of the lattice is heterogeneous, probably being a complex polymer, containing, for example, actin, tubulin, and intermediate filament protein. Similarly, the wide variation in the size of the microtrabeculae tends to preclude a single protein species as the sole component of the lattice. Recent evidence suggests that actin is one component of the microtrabecular lattice in the cell cortex of Dictyostelium discoidium. For example, it has recently been shown that random three-dimensional lattices can be formed in vitro from actin and a $M_{\mathrm{r}}=120,000$ actin-binding protein (i.e., a gelation factor; Condeelis and Wolosewick, 1980; Wolosewick et al., 1980). These actin lattices are not unlike the larger (6- to 12-nm diameter) microtrabeculae in the cortex of Dictyostelium. The $M_{\mathrm{r}}=120,000$ gelation factor apparently not only cross-links $\mathrm{F}$ actin filaments but also nucleates the polymerization of $\mathrm{G}$ actin from the sides of actin filaments. The structure of the reconstructed actin gel (i.e., actin plus the $M_{\mathrm{r}}=120,000$ gelation factor) is a random network of filaments (4 to $15 \mathrm{~nm}$ diameter) that bifurcate and form end-to-side attachments, resulting in an anastomosing net. If the ratio of the gelation factor is varied, the morphology of the lattice changes significantly from long thick unbranched filaments at low ratios to short, thin, highly branched filaments at high ratios. The reconstructed actin lattices remarkably resemble the lattice seen in the cortex of Dictyostelium discoidium (Condeelis and Wolosewick, 1980). In addition, immunofluorescent localization of the gelation factor is restricted solely to the cortical regions (Condeelis and Geosits, 1982).

It is intriguing to consider the possibility that a contractile, nonrandom lattice composed, at least in part, of actin may be responsible for the translocation of secretory granules. The best evidence to date for the participation of the lattice in intracellular motility comes from the work of Byers and Porter (1977) and Luby and Porter (1980) on pigment granule movement in the erythrophore of Holocentrus. They have shown clearly that the microtrabecular lattice undergoes very rapid deformation and re-formation during pigment granule translocation. As pigment granules aggregate in the cell center, the microtrabecular lattice apparently contracts as a whole and the lattice is deformed into the cell cortex. It is restructured during pigment granule dispersion along radially aligned microtubules. The process has been demonstrated to be energy dependent and it has been postulated that the potential energy is stored in the microtrabecular lattice by ATP-dependent processes (Luby and Porter, 1980).

Other examples of the MTL in intracellular motility in axons have been investigated and related to structure and function. Ellisman and Porter (1980) have demonstrated by a variety of electron microscopical techniques (including PEG embedding) that the axoplasm is constructed in similar fashion as the cytoplasm of whole cells. That is, a three-dimensional lattice constructed of microtubules, neurofilaments, cisternae of the synaptic endoplasmic reticulum, multivesicular bodies, mitochondria, and the microtrabeculae has been documented in axons. They have convincingly related this structure to

Figure 7. Stereo image of a preganglionic nerve ending forming a synapse onto a chromaffin cell. In the nerve terminal (single asterisk), the synaptic vesicles $(v)$ are clearly seen to be enmeshed in the microtrabecular lattice (arrowheads). The postsynaptic density in the chromaffin cell (double asterisks) is quite prominent. The microtrabeculae are easily recognized and form a characteristic three-dimensional continuum. A portion of the chromaffin cell is seen through the cytoplasm of the axon terminal giving the mistaken impression of continuity between cells. The apparent microtrabecular continuities are actually part of the chromaffin cell. White arrow, coated pit. Magnification, $\times 82,500$. 
the highly dynamic process of axoplasmic flow. Similarly, Lasek and co-workers (Lasek and Hoffman, 1976; Black and Lasek, 1980) have demonstrated the putative physiological correlate to the morphological lattice structure. That is, the slow components, $a$ and $b$, of axoplasmic transport travel as units although at different rates (e.g., tubulin and neurofilament protein in slow component $a$; actin, clathrin, calmodulin, and myosin-like proteins in slow component $b$ ). The speculation has been raised that the proteins of the slow component $b$ are components of the microtrabecular lattice (Ellisman and Porter, 1980).

The various lines of evidence emerging on the cytoplasmic ground substance point to the existence of an organized dynamic structural component that is involved in intracellular motility. This concept is of particular importance to the observations of this report. The epinephrine and norepinephrine granules of chromaffin cells and the synaptic vesicles of preganglionic nerve endings are contained in the microtrabecular lattice. These granules and vesicles must move to their site of action, i.e., the plasma membrane where neurotransmitters are released. Although the erythrophores, chromaffin cells, and neurons are distinctly different cell types, the features common to them for our purposes are: (1) membranebound structures that undergo nonrandom movement and (2) the microtrabecular lattice. Thus, the earlier observations on chromaffin cells and preganglionic endings now have added significance. Some of these are: (1) the presence of actomyosin, tropomyosin, and troponin in chromaffin cells and neurons (Puszkin and Berl, 1972; Puszkin et al., 1968; Berl et al., 1973; Fine et al., 1973, 1975; Puszkin and Kochwa, 1974; Douglas, 1975; Trifaro and IJlpian, 1975, 1976; Kuo and Coffee, 1976a, b; Creutz, 1977; Trifaro, 1977; Banks et al., 1978; Unsicker et al., 1978); (2) the involvement of ATP and $\mathrm{Ca}^{2+}$ as mediators of the secretion phenomenon (Poisner and Trifaro, 1967; Matsuda et al., 1968; Oka et al., 1972); and (3) in vitro documentation of the ability of chromaffin granules to bind muscle actin and myosin and the interaction of actin and regulatory proteins of synaptic vesicles (Smith and Winkler, 1972; Puszkin and Kochwa, 1974; Burridge and Phillips, 1975; Tashiro and Stadler, 1978; Fine and Bray, 1971). The significance of the above observations and those of this report is that an ultrastructural correlate can be assigned to the dynamic processes of vesicle and granule movement and possibly neurotransmitter release. Although this report is a morphological description, the evidence from other sources compels us to speculate that the microtrabecular lattice is an ultrastructural representation of this dynamic process. The microtrabecular lattice may act as a contractile, viscoelastic gel providing for the movement of granules and vesicles, the process being mediated by the availability of energy-rich molecules (e.g., ATP), local fluctuations in ionic environment (e.g., $\mathrm{Ca}^{2+}$ ), and the regulatory role of actin-binding proteins.

\section{References}

Banks, P., M. Sharrard, and C. Peace (1978) The formation of actin-containing gels by extracts of bovine splenic nerve. Neuroscience 3: 1109-1116.

Becker, R. P., J. J. Wolosewick, and J. Ross-Stanton (1981) Cell fine structure as revealed in desiccator dried resinless sections. 39th Annual Proceedings of the Electron Microscopy Society of America, pp. 622-623.

Berl, S., S. Puszkin, and W. J. Nicklas (1973) Actomyosin-like protein in brain. Science 179: 441-446.

Black, M. M., and R. J. Lasek (1980) Slow components of axonal transport: Two cytoskeletal networks. J. Cell Biol. 86: 616-623.

Rurridge, K., and J. H. Phillips (1975) Association of actin and myosin with secretory granule membranes. Nature 254: 526529.

Byers, H. R., and K. R. Porter (1977) Transformation in the structure of the cytoplasmic ground substance in erythrophores during pigment aggregation and dispersion. I. A study using whole-cell preparations in stereo high voltage electron microscopy. J. Cell Biol. 75: 541-558.

Cohen, R. S., and P. Siekevitz (1978) The form of the postsynaptic density: A serial section study. J. Cell Biol. 78: 34-46.

Cohen, R. S., F. Blomberg, K. Berzins, and P. Siekevitz (1977) The structure of postsynaptic densities isolated from dog cerebral cortex. I. Overall morphology and protein composition. J. Cell Biol. 74: 181-203.

Condeelis, J., and S. Geosits (1982) Isolation of a new actin binding protein from Dictyostelium discoidium. J. Biol. Chem., in press.

Condeelis, J., and J. Wolosewick (1980) The actin lattice: Composition, structure and membrane attachment. 38th Annual Proceedings of the Electron Microscopy Society of America, pp. 420-423.

Coupland, R. E. (1965) Electron microscopic observations on the structure of the rat adrenal medulla. J. Anat. 99: 231254.

Creutz, C. E. (1977) Isolation, characterization and localization of bovine adrenal medullary myosin. Cell Tissue Res. 178: 17-38.

Douglas, W. W. (1975) Secremotor control of adrenal medullary secretion: Synaptic membrane and ionic events in stimulussecretion coupling. In Handbook of Physiology. Vol. 6: Endocrinology, H. Blaschko, G. Sayers, and A. D. Smith, eds., pp. 367-388, American Physiological Society, Bethesda, MD.

Elfvin, L. G. (1965) The fine structure of the cell surface of chromaffin cells in the rat adrenal medulla. J. Ultrastruct. Res. 12: 263-286.

Ellisman, M. H., and K. R. Porter (1980) Microtrabecular structure of the exoplasmic inatrix: Visualization of crosslinking structures and their distribution. J. Cell Biol. 87: 464479.

Fine, R. E., and D. Bray (1971) Actin in growing nerve cells. Nature 234: 115-118.

Fine, R. E., A. L. Blitz, S. E. Hitchcook, and B. Kaminer (1973) Tropomyosin in brain and growing neurons. Nature 245: $182-$ 186.

Fine, R. E., W. Lehman, J. Head, and A. Blitz (1975) Troponin $\mathrm{C}$ in brain. Nature 258: 260-262.

Heuser, J. E., and T. S. Reese (1977) The structure of the synapse. In Handbook of the Nervous System, Vol. 1, American Physiological Society, Rockville, MD.

Kuo, I. C. Y., and C. J. Coffee (1976a) Purification and characterization of a troponin-C-like protein from bovine adrenal medulla. J. Biol. Chem. 251: 1603-1609.

Kuo, I. C. Y., and C. Y. Coffee (1976b) Bovine adrenal medulla troponin-C. Demonstration of a calcium-dependent conformational change. J. Biol. Chem. 251: 6315-6319.

Lasek, R. J., and P. N. Hoffman (1976) The neuronal cytoskeleton, axonal transport and axonal growth. Cold Spring Harbor Conf. Cell Proliferation 3: 1021-1049.

LeBeux, Y. J., and J. Willemot (1975a) An ultrastructural study of the microfilaments in rat brain by means of heavy meromyosin labelling. I. The perikaryon, the dendrites and the axon. Cell Tissue Res. 160: 1-36. 
LeBeux, Y. J., and J. Willemot (1975b) An ultrastructural study of the microfilaments in rat brain by means of E-PTA staining and heavy meromyosin labelling. II. The synapses. Cell Tissue Res. 160: 37-68.

Luby, K. J., and K. R. Porter (1980) The control of pigment migration in isolated erythrophores of Holocentrus ascensionis (Osbeck). I. Energy requirements. Cell 21: 13-213.

Matsuda, T., F. Hata, and H. Yoshida (1968) Stimulatory effect of $\mathrm{Na}^{+}$and ATP on the release of acetylcholine from synaptic vesicles. Biochim. Biophys. Acta 150: 739-741.

Oka, M., F. Izumi, and T. Kashimoto (1972) Effects of cytoplasmic and microsomal fractions on ATP- $\mathrm{Mg}^{++}$stimulated catecholamine release from isolated adrenomedullary granules. Jpn. J. Pharmacol. 22: 207-214.

Pappas, G. D., and S. G. Waxman (1972) Synaptic fine structure: Morphological correlates of chemical and electrotonic transmission. In Structure and Function of Synapses, G. D. Pappas and D. P. Purpura, eds., pp. 1-43, Raven Press, New York.

Poisner, A. M., and J. M. Trifaro (1967) The role of ATP and ATPase in the release of catecholamines from the adrenal medulla. I. ATP-evoked release of catecholamines, ATP, and protein from isolated chromaffin granules. Mol. Pharmacol. 3: 561-571.

Puszkin, S. and S. Berl (1972) Actomyosin-like protein from brain: Separation and characterization of the actin-like component. Biochim. Biophys. Acta 256: 695-704.

Puszkin, S., and S. Kochwa (1974) Regulation of neurotransmitter release by a complex of actin with relaxing protein isolated from rat brain synatosomes. J. Biol. Chem. 269: 7711-7714.

Puszkin, S., S. Berl, T. Puszkin, and D. D. Clarke (1968) Actomyosin-like protein isolated from mammalian brain. Science 160: 170-171.
Smith, A. D., and H. Winkler (1972) Fundamental mechanisms in the release of catecholamines. In Handbook of Experimental Pharmacology, H. Blaschko and E. Muscholl, eds., Vol. 33, pp. 538-617, Springer-Verlag, Berlin.

Tashiro, T., and H. Stadler (1978) Chemical composition of cholinergic synaptic vesicles from Torpedo marmorata based on improved purification. Eur. J. Biochem. 90: 479-487.

Trifaro, J. M. (1977) Common mechanisms of hormone secretion. Annu. Rev. Pharmacol. Toxicol. 17: 27-47.

Trifaro, J. M., and C. Ulpian (1975) Actomyosin-like protein isolated from the adrenal medulla. FEBS Lett. 57: 198-202.

Trifaro, J. M., and C. Ulpian (1976) Isolation and characterization of myosin from adrenal medulla. Neuroscience $1: 483-$ 488.

Unsicker, K., D. Dreckhahn, U. Groschel-Stewart, U. Schumacher, and G. H. Griesser (1978) Immunohistochemical evidence of myosin in peripheral nerves and spinal cord of the rat. Neuroscience 3: 301-306.

Wolosewick, J. J. (1980) The application of polyethylene glycol (PEG) to electron microscopy. J. Cell Biol. 86: 675-681.

Wolosewick, J. J., and K. R. Porter (1976) Stereo high voltage electron microscopy of whole cells of the human diploid line WI-38. Am. J. Anat. 147: 303-323.

Wolosewick, J. J., and K. R. Porter (1979) Microtrabecular lattice of the cytoplasmic ground substance. Artifact or reality. J. Cell Biol. 82: 114-139.

Wolosewick, J. J., R. P. Becker, and J. S. Condeelis (1980) The appearance of microtubules and the cytoplasmic ground substance in resinless sections of cells. In Microtubules and Microtubule Inhibitors, M. DeBrabander and J. DeMey, eds., pp. 3-16, Elsevier/North-Holland Biomedical Press, Amsterdam. 